Die mittlere Dauer der Periode, mit welcher ich | hängt von dem wahrscheinlichen Fehler der beiden, für die Jahre $1840-1875$ alle Reductionen ausführte, bestimmte ich $=2^{\mathfrak{t} 2} 20^{\mathrm{h}} 48^{\mathrm{m}} 53^{\mathrm{s}} 60 \pm 0^{\mathrm{s}} 060$, wo die letzte Zahl nicht den wahrscheinlichen Fehler bedeutet, sondern die mögliche Grenze der Unsicherheit, die ab-

um 4459 Perioden von einander entfernten Epochen.

Athen, den 14. Januar 1876.

J. F. Julius Schmidt.

\title{
Beobachtungen von Doppelsternen (Fortsetzung von Nr. 2076).
} Von Baron v. Dembonshi.

Pour les Mésures Micrometriques Antérieures voir les Volumes des A. N. 62, 66, 73, 75, 76, 77, 79, 83.

13. Cephei 318.

\begin{tabular}{|c|c|c|c|c|c|c|c|c|}
\hline & & & & & & & & \\
\hline 1864.691 & $22^{\mathrm{h}} 25^{\mathrm{m}}$ & 500 & & $0^{\prime \prime} 4$ & $103^{\circ} 0$ & 7.0 & 7.2 & \\
\hline 1865.935 & 2223 & 500 & & 0.5 & 104.0 & 6.2 & 6.7 & \\
\hline 1869.516 & 2148 & 500 & & 0.6 & 100.0 & 6.5 & 7.0 & \\
\hline 1874.823 & 2330 & 670 & & 0.47 & 96.2 & 6.0 & 6.5 & \\
\hline 1875.715 & 2341 & 500 & & 0.58 & 97.2 & 6.5 & 7.0 & \\
\hline 1870.16 & & & & 0.525 & 100.08 & 6.4 & 6.9 blanches & 5 Jours \\
\hline 1863.00 & & & & 0.5 & 103.56 & & & $5 \quad$ \\
\hline & & & & & 0. $\eta \mathrm{Cas}$ & iopeia & & \\
\hline 1874.441 & 1931 & 500 & & 5.94 & 141.2 & 3.5 & 7.0 & \\
\hline .497 & 2026 & $"$ & & 5.75 & 142.9 & 4.0 & 7.5 & \\
\hline .568 & 218 & 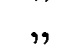 & & 5.88 & 142.8 & 3.5 & 7.0 & \\
\hline .584 & 1623 & 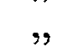 & $*$ & & 143.5 & & & \\
\hline .667 & 2025 & 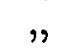 & & 5.81 & 143.4 & 3.5 & 7.0 & \\
\hline .803 & 2015 & 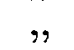 & & 5.89 & 143.4 & 4.0 & 7.5 & \\
\hline .856 & 2016 & $"$ & * & 5.71 & 144.3 & 3.5 & 7.0 & \\
\hline 1875.367 & 1922 & 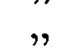 & $*$ & 5.73 & 145.5 & 3.5 & 7.0 & \\
\hline .509 & 1934 & , & & 5.70 & $14 \check{.} .5$ & 3.5 & 7.0 & \\
\hline .558 & 1550 & 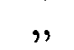 & * & & 146.4 & & & \\
\hline .627 & 1943 & $n$ & & 5.64 & 146.0 & 3.5 & 7.0 & \\
\hline .717 & 2020 & " & & 5.68 & 147.3 & 4.0 & 7.0 & \\
\hline .830 & 1946 & ", & * & 5.61 & 146.8 & 4.0 & 7.0 & \\
\hline 1875.01 & & & & 5.758 & 144.54 & 3.6 . & une-clair 7.1 & coul. rose \\
\hline 1873.18 & & & & 5.864 & 139.97 & & & \\
\hline & & & & & 36 And & omed & & \\
\hline 1872.628 & 044 & 500 & & 1.40 & 352.5 & 6.0 & 6.2 & \\
\hline .689 & 059 & 300 & & 1.29 & 352.5 & 5.7 & 6.2 & \\
\hline 1873.647 & 056 & 500 & & 1.31 & 352.2 & .6 .0 & 6.2 & \\
\hline .719 & 018 & 670 & & 1.40 & 352.9 & 6.0 & 6.2 & \\
\hline 1874.598 & 044 & 500 & & 1.32 & 354.1 & 6.0 & 6.2 & \\
\hline .853 & 050 & 500 & & 1.33 & 354.1 & 6.0 & 6.2 & \\
\hline .960 & 042 & 500 & & 1.15 & 355.0 & 6.0 & 6.5 & \\
\hline 1875.564 & 031 & 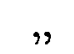 & * & 1.22 & 356.0 & 6.0 & 6.5 & \\
\hline .676 & 215 & $"$ & & 1.28 & 355.4 & 6.0 & 6.5 & \\
\hline 1874.26 & & & & 1.300 & 353.86 & 6.0 & 6.3 jaunes & 9 Jours \\
\hline 1870.38 & & & & 1.310 & 350.82 & & & $6 \%$ \\
\hline & & & & & 160. $\mathrm{Ce}$ & hei 49 & & \\
\hline 1872.683 & 142 & 500 & & 1.12 & 26.6 & 5.5 & 7.0 & \\
\hline 1873.900 & 2350 & 670 & & 0.93 & 26.7 & & & \\
\hline 1874.179 & 510 & 500 & * & 0.87 & 27.6 & 5.5 & 7.0 & \\
\hline
\end{tabular}




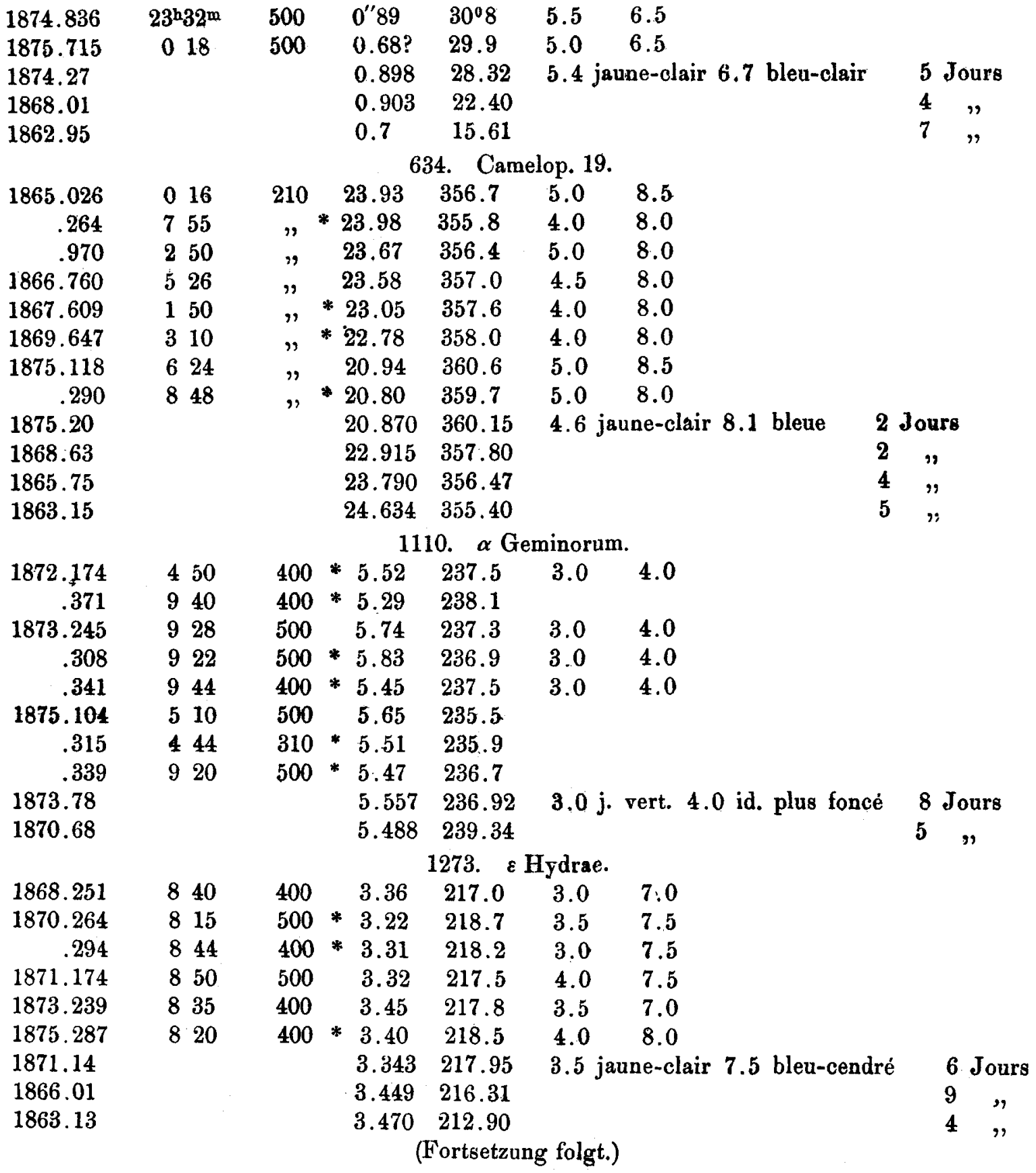

In h a l t :

Zu Nr. 2077. J. F. Julius Schmidt. Ueber $\beta$ Persei (Algol). 193. - Dembowski. Pour les Mèsưres Micrometriques Antérieures. 205. 